\title{
An Escalating Dose/Multiple High-Dose Binge Pattern of Amphetamine Administration Results in Differential Changes in the Extracellular Dopamine Response Profiles in Caudate-Putamen and Nucleus Accumbens
}

\author{
Ronald Kuczenski and David S. Segal \\ Psychiatry Department, School of Medicine, University of California San Diego, La Jolla, California 92093
}

\begin{abstract}
Amphetamine (AMPH)-induced psychosis is most frequently associated with a chronic high-dose "binge" or "run" pattern of stimulant abuse, generally preceded by a period of gradually escalating doses of the drug. We showed previously that animals subjected to such a regimen of AMPH administration developed, over multiple daily binges, a unique pattern of behavioral response that included a decrease in stereotypy and a pronounced increase in locomotion. Because of the involvement of mesolimbic and mesostriatal dopamine (DA) pathways in locomotion and stereotypy, respectively, we hypothesized that a persistent shift in the relative magnitude of caudateputamen (CP) and nucleus accumbens (NAC) DA transmission may contribute to this altered behavioral profile. To test this hypothesis, we examined CP and NAC extracellular DA in response to multiple high-dose AMPH binges. Our results re-
\end{abstract}

vealed that with multiple binges the CP DA response but not the NAC response developed a profound tolerance/tachyphylaxis to the drug-induced increase in extracellular transmitter. These differential regional response alterations seem to correspond to the shift in the relative expression of stereotypy and locomotion. We hypothesize that changes in DA synthesis, perhaps mediated by regionally specific adaptations in DA autoreceptor function, contribute to the differential extracellular transmitter response profiles, and suggest that these neurochemical changes may have important implications for the mechanisms underlying the addictive and psychotogenic properties of AMPH.

Key words: amphetamine; binge; psychosis; microdialysis; dopamine; caudate-putamen; nucleus accumbens; stereotypy; locomotion
Amphetamine (AMPH)-induced psychosis is most frequently associated with a chronic high-dose "binge" or "run" pattern of stimulant abuse (Davis and Schlemmer, 1980; Angrist, 1994b; Gawin and Khalsa, 1996). Prevailing evidence suggests that to achieve the doses and frequency of drug administration associated with this pattern of drug use, abusers generally precede "bingeing" by a period of gradually escalating doses of the drug (Angrist, 1987, 1994a,b; Gawin, 1991; Gawin and Khalsa, 1996). Presumably, the tolerance that develops to the sympathomimetic effects of the stimulants (Fischman and Schuster, 1974, 1977; Schmidt et al., 1985a; Angrist, 1994b; Schuster and Fischman, 1996) allows the abuser to survive the higher, more frequent dosing used in the binge.

To accurately assess mechanisms that may be associated with stimulant abuse and the development of stimulant psychosis, we have attempted to simulate this high-dose pattern of stimulant abuse in a series of studies in which rats were exposed to gradually escalating doses of AMPH or methamphetamine (METH) before frequent multiple daily administrations (binges) of relatively high doses of the drug (Segal and Kuczenski, 1997a,b). Animals subjected to these treatments developed, over multiple daily binges, a unique pattern of behavioral response that included elements of

Received Jan. 24, 1997; revised March 11, 1997; accepted March 20, 1997.

This work was supported in part by Public Health Service (PHS) Grants DA-04157 and DA-01568 and PHS Research Scientist Award MH-70183 to D.S.S. Excellent technical assistance was provided by Molly Roznoski and Joseph Higgins.

Correspondence should be addressed to Dr. Ronald Kuczenski, Psychiatry Department (0603), University of California San Diego School of Medicine, 9500 Gilman Drive, La Jolla, CA 92093.

Copyright (C) 1997 Society for Neuroscience $0270-6474 / 97 / 174441-07 \$ 05.00 / 0$ both tolerance (stereotypy response) and sensitization (locomotor response) (Segal and Kuczenski, 1997a). Because of the involvement of mesolimbic and mesostriatal dopamine (DA) pathways in locomotion and stereotypy, respectively (Roberts et al., 1975; Kelly and Iversen, 1976; Costall and Naylor, 1977; Sessions et al., 1980; Swerdlow et al., 1986), we hypothesized that a persistent shift in the relative magnitude of caudate-putamen (CP) and nucleus accumbens (NAC) DA transmission may contribute to the altered behavioral profile associated with this escalating dosebinge pattern of drug administration (Segal and Kuczenski, 1997a). To test this hypothesis, we examined the CP and NAC DA response profiles to multiple high-dose AMPH binges. Our results revealed that the CP DA response but not the NAC DA response developed a profound tolerance/tachyphylaxis to the druginduced increase in extracellular transmitter. These differential regional response alterations seem to correspond to the shift in the relative expression of stereotypy and locomotion.

\section{MATERIALS AND METHODS}

Subjects. Male Sprague Dawley rats (obtained from Simonsen Labs, Gilroy, CA), weighing 325-350 gm at the beginning of drug treatment, were housed for at least 1 week before experimental manipulation in groups of two or three in wire mesh cages in a temperature- and humidity-controlled room, maintained on a $14 \mathrm{hr}$ light/10 hr dark cycle (5:00 A.M.-7:00 P.M.). Animals were stereotaxically implanted with guide cannulae using procedures described previously in detail (Kuczenski and Segal, 1989). Guide cannulae extended $2.6 \mathrm{~mm}$ below the surface of the skull and were aimed at the CP (1.0 mm anterior to bregma, 2.8 $\mathrm{mm}$ lateral, and $6.2 \mathrm{~mm}$ below dura) and the NAC (2.2 $\mathrm{mm}$ anterior, 1.5 $\mathrm{mm}$ lateral, $7.8 \mathrm{~mm}$ below dura). After surgery, animals were housed individually and allowed at least 1 week to recover before they received any treatment. 
Table 1. Baseline extracellular dopamine and metabolites (nM)

\begin{tabular}{|c|c|c|c|c|c|c|}
\hline \multirow[b]{2}{*}{ Group } & \multicolumn{3}{|c|}{ Caudate-putamen } & \multicolumn{3}{|c|}{ Nucleus accumbens } \\
\hline & DA & DOPAC & HVA & $\mathrm{DA}$ & DOPAC & HVA \\
\hline Acute (5) & $19.4 \pm 2.5$ & $6160 \pm 595$ & $3655 \pm 579$ & $11.5 \pm 2.0$ & $5336 \pm 738$ & $1543 \pm 177$ \\
\hline ED/Run 1 (12) & $21.2 \pm 2.7$ & $6526 \pm 429$ & $3266 \pm 255$ & $9.7 \pm 1.1$ & $6005 \pm 442$ & $1634 \pm 137$ \\
\hline ED/Run 9 (13) & $18.3 \pm 1.3$ & $5238 \pm 375$ & $2548 \pm 218^{*}$ & $9.8 \pm 2.1$ & $5848 \pm 699$ & $1559 \pm 173$ \\
\hline
\end{tabular}

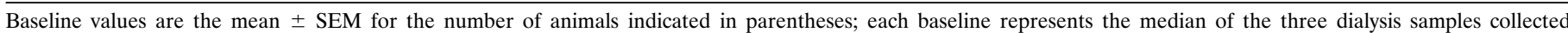
immediately before the first drug injection. ${ }^{*} p<0.05(t>2.15)$ compared with the Acute and the escalating dose (ED)/Run 1 groups.

Drugs. D-AMPH sulfate (National Insitute of Drug Abuse) was administered subcutaneously in saline $(2 \mathrm{ml} / \mathrm{kg}$ to avoid local irritation that might be produced by high concentrations). Doses refer to the free base.

Apparatus. Dialysis was performed in custom-designed activity chambers (Segal and Kuczenski, 1987). Briefly, each of the chambers $(30 \times$ $20 \times 38 \mathrm{~cm}$ ) was located in a sound-attenuated cabinet maintained on a $14 \mathrm{hr}$ light $/ 10 \mathrm{hr}$ dark cycle with constant temperature and humidity. Food and water were available ad libitum. Representative animals selected randomly from each group were videotaped for $60 \mathrm{sec}$ at successive $5 \mathrm{~min}$ intervals throughout the drug response to assess the quantitative and qualitative features of the response during both the stereotypy and poststereotypy phases. Raters who were unaware of the specific experimental conditions subsequently rated the videotapes on the basis of behavior ethograms and rating procedures established previously (Segal and Kuczenski, 1987). Stereotypy was assessed as the percentage of the observation interval during which the animal displayed each specific behavior. The appearance of other atypical responses or behavior patterns was noted by the rater after each sampling interval.

General procedures. Animals were first exposed to the escalating dose regimen or to the escalating dose regimen and eight daily four-injection runs and were then monitored for $\mathrm{CP}$ and NAC DA during the course of a subsequent four-injection run. Control animals were pretreated with saline and then received three injections of saline followed by a single injection of AMPH $(8.0 \mathrm{mg} / \mathrm{kg})$ during the run session. For the escalating dose phase, animals received three injections per day for $4 \mathrm{~d}$, beginning with a $1.0 \mathrm{mg} / \mathrm{kg}$ dose of AMPH; the dose was incremented by $1 \mathrm{mg} / \mathrm{kg}$ per injection and ended with a dose of $8 \mathrm{mg} / \mathrm{kg}$ on the fourth day of the cycle. Another group, receiving an equal number of saline injections, served as the control. All animals received saline only on day 5 , and runs were initiated on day 6 . During the run phase, animals received $8 \mathrm{mg} / \mathrm{kg}$ AMPH every $2 \mathrm{hr}$ for four injections, beginning at 8 A.M. and ending at 2 P.M. All animals received saline only on the day before dialysis. Thus, dialysis was performed $36 \mathrm{hr}$ after the last AMPH injection of the escalating dose pretreatment or the eighth $8 \mathrm{mg} / \mathrm{kg}$ AMPH run.

Each rat was placed in an experimental chamber, and the dialysis probes were inserted on the day before the test (3:00-4:00 P.M.) to allow for acclimation to the test environment and for adequate equilibration of the dialysis probes. Concentric microdialysis probes were constructed of Spectra/Por hollow fiber (cut-off molecular weight 6000; outer diameter $250 \mu$ ) according to the method of Robinson and Whishaw (1988), with modifications as described previously (Kuczenski and Segal, 1989). The length of the active probe membrane was $3 \mathrm{~mm}$ for $\mathrm{CP}$ and $1.25 \mathrm{~mm}$ for NAC. Probes were perfused with artificial CSF $\left(147 \mathrm{~mm} \mathrm{NaCl}, 1.2 \mathrm{mM} \mathrm{CaCl}_{2}, 0.9 \mathrm{mM} \mathrm{MgCl}_{2}, 4.0 \mathrm{mM} \mathrm{KCl}\right)$ delivered by a microinfusion pump $(0.5 \mu \mathrm{l} / \mathrm{min})$ via $50 \mathrm{~cm}$ of Micro-line ethyl vinyl acetate tubing connected to a fluid swivel. Dialysate was collected through glass capillary tubing into vials containing $20 \mu \mathrm{l}$ of $25 \%$ methanol, $0.2 \mathrm{~m}$ sodium citrate, $\mathrm{pH}$ 3.8. Under these conditions, dialysate DA and metabolites were stable throughout the collection and analysis interval. Samples were collected outside the experimental chamber to avoid disturbing the animal. Individual probe recoveries were estimated by sampling a standard DA solution in vitro. At the end of the experiment, each animal was perfused with formalin for histological verification of probe placements. All animals were dialyzed in both $\mathrm{CP}$ and NAC; probe failures and/or inaccurate probe placements account for different numbers presented in Figures 2 and 3.

Dialysate samples were collected every $30 \mathrm{~min}$ and were assayed for DA, 3,4-dihydroxyphenylacetic acid (DOPAC), and homovanillic acid (HVA) by HPLC with electrochemical (EC) detection. The HPLC-EC consisted of a $100 \times 4.6 \mathrm{~mm}$ ODS-C18 $3 \mu$ column (Regis) maintained at $40^{\circ} \mathrm{C}$. Mobile phase $\left(0.05 \mathrm{M}\right.$ citric acid, $7 \%$ methanol, $0.1 \mathrm{~mm} \mathrm{Na}_{2}$ EDTA, and $0.2 \mathrm{~mm}$ octane sulfonate adjusted to $\mathrm{pH} 4.0-4.5$ ) was delivered at 0.6 $\mathrm{ml} / \mathrm{min}$ by a Waters model 510 pump (Waters Associates, Milford, MA). Amines were detected with a Waters 460 detector with a glassy carbon electrode maintained at $+0.65 \mathrm{~V}$ relative to a $\mathrm{Ag} / \mathrm{AgCl}$ reference electrode. Concentrations were estimated from peak heights using a Waters Maxima 820 data station. Substances in the dialysates were corrected for individual probe recoveries to account for this source of variability, and although the exact relationship between dialysate concentration and actual extracellular transmitter content is not clear (Wages et al., 1986; Church and Justice, 1987; Benveniste et al., 1989; Stahle et al., 1991), values are presented as dialysate concentration to allow for meaningful comparisons with other data in the literature. For determination of tissue DA levels, tissue samples were prepared according to Schmidt et al. (1990) before chromatographic analysis.

Data analysis. Behavioral and neurochemical data were statistically analyzed using repeated measures ANOVA and $t$ tests with Bonferroni corrections for specific group/time comparisons.

\section{RESULTS}

\section{Behavior}

As described previously (Segal and Kuczenski, 1997a), the behavioral response to the first three injections of the initial $8 \mathrm{mg} / \mathrm{kg}$ AMPH run consisted primarily of oral stereotypy (continuous licking and biting) in the absence of locomotion (Fig. 1). In contrast, during the ninth run, oral stereotypy diminished, and there was a corresponding increase in repetitive head movements, typically associated with lower doses of the drug. In addition, by the fourth injection of the ninth run, stereotypy was interrupted frequently by episodes of locomotion. Tolerance was particularly apparent after the fourth injection of the ninth run, where a more complete characterization of the late phases of the response was possible. Compared with both the acute and first run groups, animals receiving the fourth injection of the ninth run exhibited a pronounced decrease in the duration of continuous stereotypy and a correspondingly more rapid appearance of poststereotypy locomotion. In addition, the poststereotypy phase was characterized by frequent episodes of burst-like locomotion during which crossovers were made within rapid succession of each other, and the behavior between run-induced bursting seemed to be more intense and considerably less varied than that produced by the other treatments (i.e., primarily nose poking) (data not shown; for more detailed characterization, see Segal and Kuczenski, 1997a,b).

\section{Neurochemistry}

The CP and NAC DA responses to the first and ninth AMPH runs are compared to an acute injection of AMPH in Figures 2 and 3. Baseline DA and metabolite levels in microdialysates from saline and escalating dose pretreated animals were not significantly different in either CP or NAC (Table 1). Likewise, baseline levels of DA and metabolites in NAC and of DA in CP were not altered by exposure to eight runs; however, after eight runs, CP HVA levels were significantly decreased compared with both escalating dose and saline pretreated groups $(t>2.15 ; p<0.05)$, and DOPAC levels trended lower $(p=0.08)$. 

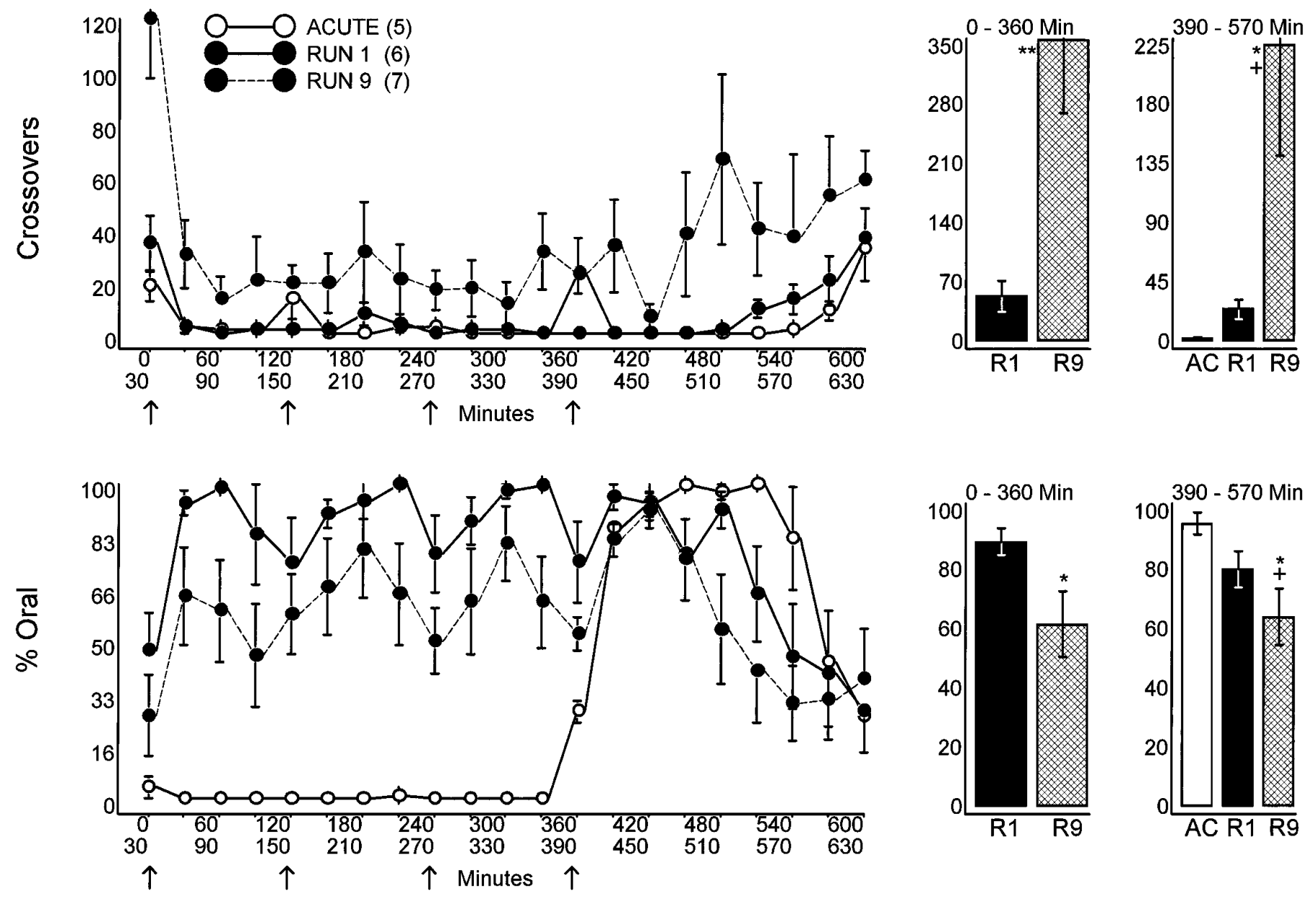

Figure 1. Locomotor and stereotypy responses of dialyzed animals during administration of an $8 \mathrm{mg} / \mathrm{kg}$ AMPH run. Groups of animals were pretreated with the escalating dose regimen (RUN 1), escalating dose and eight AMPH runs (RUN 9), or an equivalent number of saline injections (ACUTE), as described in Materials and Methods, and were exposed to saline or $8 \mathrm{mg} / \mathrm{kg}$ AMPH at $2 \mathrm{hr}$ intervals (arrows) during dialysis. Stereotypy is presented as percentage of time engaged in oral behaviors. Histograms represent the cumulated response over the indicated interval (390-570 min interval ANOVA: Crossovers, $F=5.18, p<0.05 ; \%$ Oral, $F=4.00, p<0.05)$. ${ }^{*} p<0.05$, ${ }^{*} p<0.01(t>2.57)$ compared with Run $1 ;+p<0.05(t>2.80)$ compared with ACUTE.

The escalating dose pretreatment significantly attenuated the CP DA response to the first AMPH injection of the first run (Fig. 2) but had no comparable effect on the DA response in NAC (Fig. 3 ). With successive injections during the first run, both the $\mathrm{CP}$ and NAC DA responses (peak levels and area under the curve) declined progressively. During the ninth run, the DA response in $\mathrm{CP}$ was further attenuated (Fig. 2), i.e., the response sequence began at a lower level and declined further with successive injections. In contrast to $\mathrm{CP}$, none of the NAC DA responses during the ninth run were attenuated (Fig. 3).

In parallel groups of animals, $\mathrm{CP}$ and NAC tissue levels of DA were determined $4 \mathrm{~d}$ after the last AMPH injection (Table 2). Consistent with our past results, neither the escalating dose pretreatment followed by a single $8 \mathrm{mg} / \mathrm{kg}$ run nor an acute injection of $8 \mathrm{mg} / \mathrm{kg}$ altered CP DA levels. Likewise, these treatments had no effect on NAC DA; however, whereas multiple $8 \mathrm{mg} / \mathrm{kg}$ runs had no effect on NAC DA, this treatment significantly decreased CP DA.

\section{DISCUSSION}

The results presented above reveal that the escalating dose/multiple high-dose binge pattern of AMPH administration leads to a progressive shift in the relative responses of the mesostriatal and mesoaccumbens DA systems. This shift corresponds to the gradual decrease in intensity and duration of stereotyped behaviors and the emergence of a more pronounced and qualitatively distinct locomotor component of the multiphasic behavioral profile. The decreasing prominence of the CP DA response concomitant with the replacement of focused stereotypies by locomotor activation is consistent with the presumed relative roles of $\mathrm{CP}$ and NAC DA in the appearance of these behaviors, and it suggests that these neurochemical changes play a significant role in the altered behavioral profile associated with this drug treatment regimen; however, whereas the unique behavioral changes associated with this treatment regimen require multiple binges to be fully expressed, alterations in the neurochemical profile are already evident during the first binge, and therefore cannot fully account for these behaviors. Rather, it seems that the continued progression of the shift in the regional DA responses and its persistence through multiple binges result in regionally specific changes in postsynaptic mechanisms (e.g., alterations in receptor sensitivity), which ultimately contribute to the emergent behavioral profile. 


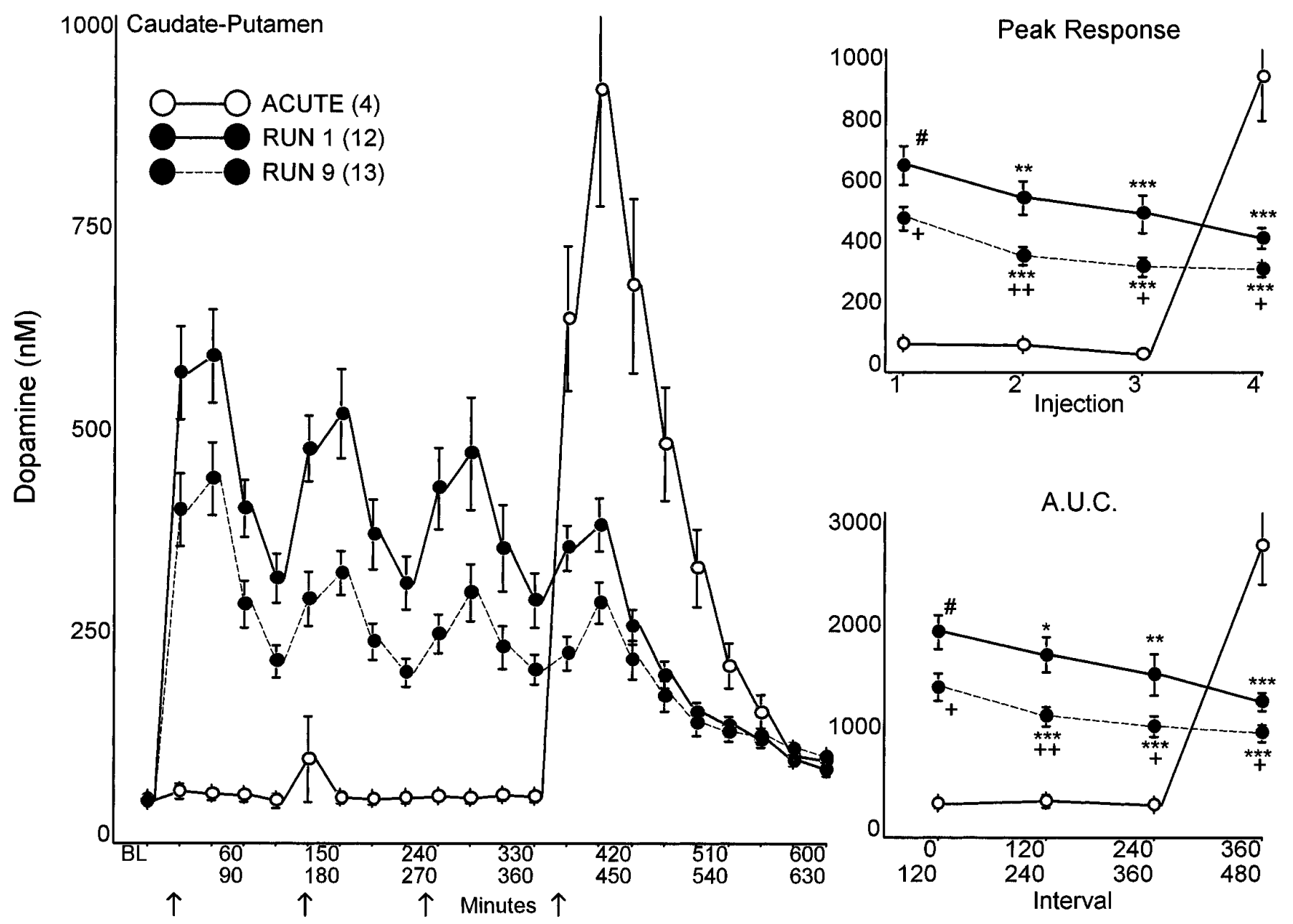

Figure 2. CP extracellular DA in response to the first and ninth $8 \mathrm{mg} / \mathrm{kg}$ AMPH run, compared with a single acute injection of $8 \mathrm{mg} / \mathrm{kg}$ AMPH. Dialysis samples were collected at $30 \mathrm{~min}$ intervals and $B L$ (baseline) represents the median value of the three samples collected immediately before the first injection. AMPH or saline was administered every $2 \mathrm{hr}$ (arrows). The Peak Response for each injection, and the area under the curve (A.U.C.) for the 120 min interval after each injection are summarized in the graphs on the right. The response to the first injection of $R U N 1$ was significantly different from the ACUTE response $(t>2.21$; \# $p<0.05)$. The responses to later injections within each run were significantly different from the first injection of the same run (RUN 1 ANOVA: Peak Response, $F=9.73, p<0.01, t>2.95 ;$ A.U.C., $F=9.50, p<0.01, t>2.25 ;$ RUN 9 ANOVA: Peak Response, $F=28.61$, $p<0.01, t>5.25 ;$ A.U.C., $F=23.05, p<0.01, t>5.41)\left({ }^{*} p<0.05, * * p<0.01, * * * p<0.001\right)$. The responses during the ninth run were significantly different from the corresponding injections during the first run $(t>2.41 ;+p<0.05,++p<0.01)$.

Table 2. Effects of multiple amphetamine runs on caudate-putamen and nucleus accumbens dopamine levels (pmol/gm tissue)

\begin{tabular}{lll} 
& Caudate-putamen & Nucleus accumbens \\
\hline Saline (6) & $99.0 \pm 5.2$ & $37.1 \pm 2.7$ \\
Acute (6) & $96.3 \pm 3.0$ & $32.0 \pm 2.3$ \\
ED/Run 1 (6) & $83.1 \pm 6.4$ & $38.0 \pm 2.4$ \\
ED/Run 9 (5) & $60.0 \pm 9.3^{* *}$ & $35.6 \pm 2.0$
\end{tabular}

Tissue levels were determined in groups of animals (numbers in parentheses) $4 \mathrm{~d}$ after the indicated treatment regimen. (Caudate-putamen ANOVA: $F=8.01, p<$ $0.001) .{ }^{* *} p<0.01(t=4.03)$ compared with the Acute group.

The shift in regional DA responsivity seems to be caused by decreases in the CP DA response throughout all phases of the drug treatment and a relative resistance of the NAC DA response to these changes. For one, only the CP DA response was attenuated to the first AMPH injection of the initial run. Second, although the NAC DA response did decrease during the first run, by the ninth run the response to each injection was identical to the acute control. In contrast, during the ninth run the $\mathrm{CP}$ responses to all of the injections declined further. It is not likely that pharmacokinetic factors contribute to the decreasing CP DA response. For one, the escalating dose regimen by itself does not alter peak AMPH levels during a subsequent challenge with AMPH (Segal and Kuczenski, 1997a). Therefore, the suppressed CP DA response to the first injection of the first run cannot be attributed to diminished accessibility of the drug to the brain. Furthermore, as would be expected from the half-life of the drug (Benet et al., 1990), during an $8 \mathrm{mg} / \mathrm{kg}$ run AMPH accumulates gradually, such that peak drug levels were $\sim 20 \%$ higher than after an acute injection (Segal and Kuczenski, 1997a). Thus, especially for the CP DA system, a profound tolerance/tachyphylaxis develops to subsequent exposure to the drug during the escalating dose-binge pattern of AMPH administration.

A progressive decline in caudate DA response has also been reported after successive injections of lower doses of both AMPH (Segal and Kuczenski, 1997b) and METH (Nash and Yamamoto, 1992; Bowyer et al., 1993; Segal and Kuczenski, 1997b; but see Weihmuller et al., 1992), and it seems likely that the prolonged AMPH-induced release of DA could result in a decrease in the 

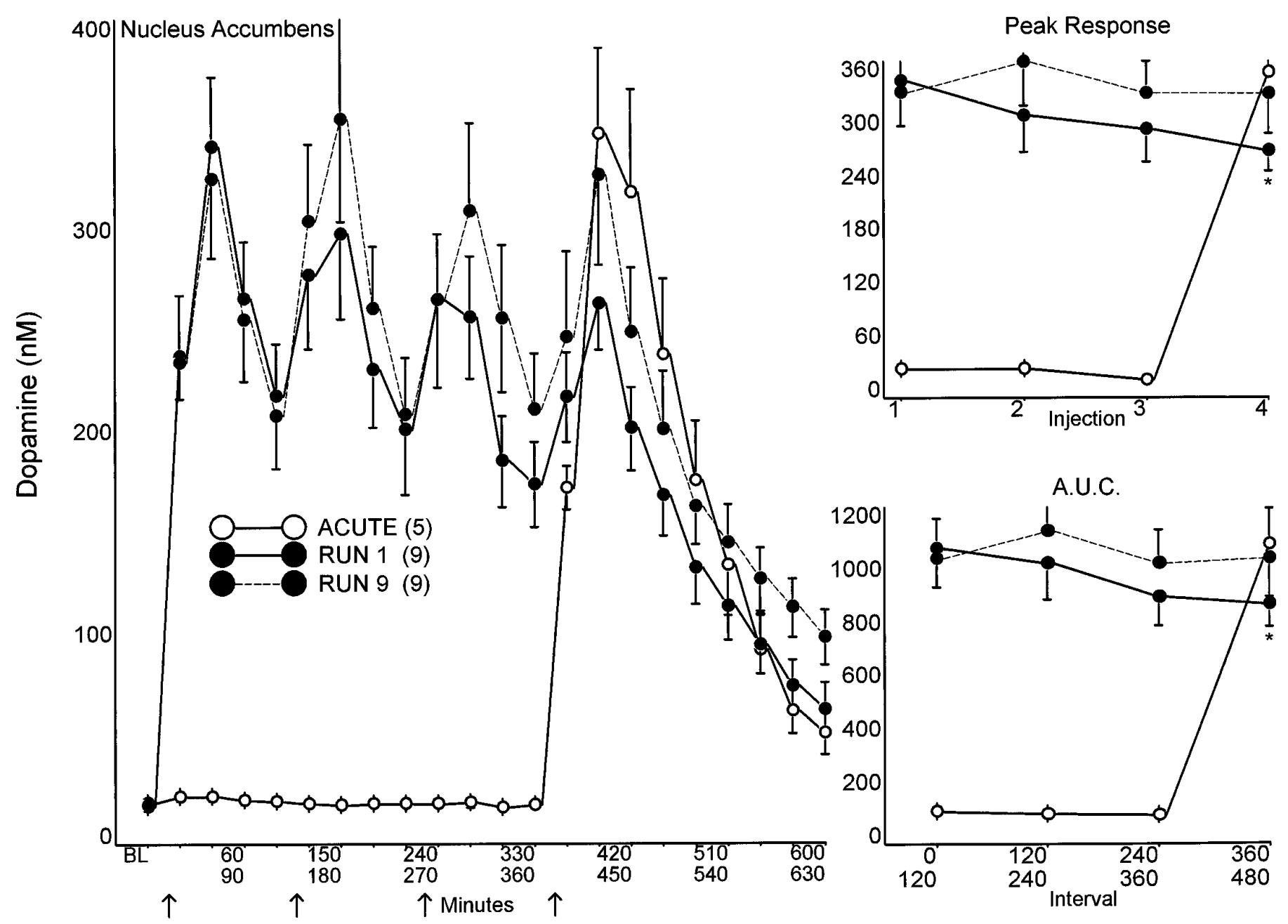

Figure 3. NAC extracellular DA in response to the first and ninth $8 \mathrm{mg} / \mathrm{kg}$ AMPH run, compared with a single acute injection of $8 \mathrm{mg} / \mathrm{kg}$ AMPH. Dialysis samples were collected at $30 \mathrm{~min}$ intervals and $B L$ (baseline) represents the median value of the three samples collected immediately before the first injection. AMPH or saline was administered every $2 \mathrm{hr}$ (arrows). The peak response for each injection, and the area under the curve (A.U.C.) for the $120 \mathrm{~min}$ interval after each injection are summarized in the graphs on the right (ANOVA: Peak Response, $F=3.58, p<0.05, t=2.51 ; A . U . C$., $F=$ $3.02, p<0.05, t=2.92) .{ }^{*} p<0.05$ compared with the first injection of the same run.

availability of relevant transmitter pools. In fact, we showed previously that CP tissue levels of DA were decreased by $\sim 20 \%$ at the fourth injection of an $8.0 \mathrm{mg} / \mathrm{kg}$ run. Along these same lines, the further attenuation of the CP DA response to the first injection of the ninth run may also be attributable to long-lasting decrements in brain DA resulting from the repeated high doses of AMPH (for reviews, see Axt et al., 1994; Gibb et al., 1994; Seiden and Sabol, 1995). Under our conditions, we observed a $20-25 \%$ decrease in CP DA after exposure of animals to four $8 \mathrm{mg} / \mathrm{kg}$ AMPH runs (Segal and Kuczenski, 1997a) and a 30-35\% decrease after nine runs (Table 1 ). These relatively small reductions in CP DA, compared with the much greater depletions in animals not previously exposed to an escalating dose pretreatment regimen (Bowyer et al., 1992; Clausing et al., 1995), are consistent with earlier evidence that lower-dose pretreatment significantly protects CP DA from the long-lasting depletion produced by subsequent high doses of the drug (Schmidt et al., 1985a,b). In this regard, earlier data suggested that $\mathrm{CP} D \mathrm{DA}$ is more responsive than is NAC DA to the depleting effects of AMPH (Ellison et al., 1978; Ellison and Eison, 1983; Castañeda et al., 1990; Swerdlow et al., 1991; Paulson and Robinson, 1995), and the results of our exper- iments are consistent with these observations. Because the $\mathrm{CP}$ and NAC DA responses to the first injection of the ninth run paralleled this selective depletion, it seems reasonable to suggest that the regionally selective tissue loss of DA contributes to the attenuated response in $\mathrm{CP}$.

Depletion of DA by itself, however, is probably not entirely responsible for tolerance of the AMPH-induced increase in $\mathrm{CP}$ DA, because the CP response to the first injection of the first run is attenuated when CP tissue levels of DA are not different from saline controls (Segal and Kuczenski, 1997a). In this regard, most evidence indicates that acute high doses of AMPH decrease DA synthesis, presumably through an indirect inhibition of tyrosine hydroxylase (TOH) activity (Kuczenski, 1977a,b, 1979; Tyler and Galloway, 1992). It also has been suggested that long-term compensatory decreases in DA synthesis result from repeated highdose stimulant administration (Bowyer and Holson, 1995). In this regard, Zhang and Angulo (1996) recently reported a decrease in TOH mRNA in substantia nigra of chronic METH-pretreated rats. A prolonged decrease in the synthesis of the rate-limiting biosynthetic enzyme (TOH) or changes in the susceptibility of the enzyme to short-term activation and/or inhibition could alter the 
availability of AMPH-releasable DA. It seems reasonable to suggest that the magnitude of compensatory decreases in DA synthesis may be related to the intensity of pretreatment. Thus, decreases in synthesis may be initiated during the escalating dose pretreatment, which even in the absence of measurable depletion of tissue DA could account for the attenuated CP DA response to the first AMPH injection after the pretreatment phase. It is also possible that reductions in DA synthesis contribute to the declining responsivity of caudate DA within the run as well. In fact, the diminished DA response to successive injections of AMPH resembles the pattern of response after DA synthesis inhibition. Inhibition of DA synthesis with $\alpha$-methyl tyrosine results in a decreased DA response to all doses of AMPH tested, even when tissue levels of DA are still substantially intact (Butcher et al., 1988; Cadoni et al., 1995) (our unpublished observations). It seems, therefore, that ongoing synthesis likely plays a critical role in maintaining the AMPH-releasable pool at a level required for a high-dose DA response. Thus, synthesis inhibition may be primarily responsible for the diminishing DA response, not only across multiple runs but also during each AMPH run as well, and a portion of the decline in tissue levels of transmitter may be a secondary consequence of inhibited synthesis.

In contrast to the declining CP DA response that was apparent throughout each phase of the treatment regimen, the NAC DA response was decreased only during the first run, and in fact peak DA after each injection of the ninth run was identical to values obtained in response to acute AMPH. These data suggest that with multiple AMPH runs, changes occur in adaptational mechanisms regulating the dynamics of the AMPH-releasable DA pool to counteract the declining NAC responsivity that was evident in the first run. One possibility is that autoreceptor-mediated inhibition of TOH may play an important role in limiting the replenishment of the cytoplasmic pool during prolonged exposure to the drug and may contribute to the decline in both the CP and NAC DA responses to successive injections of AMPH during the first run. A region-selective desensitization of synthesis-regulating autoreceptors with repeated AMPH would contribute to a more rapid replenishment of NAC DA, thereby attenuating the decline in NAC DA release in response to later injections of AMPH. Although synthesis-regulating DA autoreceptors in the NAC have not been characterized after repeated AMPH administration, the chronic administration of AMPH-like stimulants does result in desensitization of autoreceptors on DA perikarya in the ventral tegmental area (Kamata and Rebec, 1984; White and Wang, 1984; Henry et al., 1989; Wolf et al., 1994) but not of autoreceptors in the substantia nigra (Pitts et al., 1993). A similar selective desensitization of synthesis-regulating autoreceptors could account for the differential regional DA responses to multiple AMPH runs. In addition, the results of recent studies provide evidence for a selective increase in TOH mRNA in the ventral tegmental area but not in substantia nigra during withdrawal from repeated METH (Zhang and Angulo, 1996). Increased levels of TOH could also contribute to recovery of the releasable pool of DA during a binge.

Regardless of the underlying mechanisms, the persistent shift in relative responsiveness of the nigrostriatal and mesolimbic DA systems likely plays a significant role in the behavioral changes associated with the escalating dose/repeated-runs treatment paradigm. In addition, however, we have shown previously that the monoamines 5HT and NE are also altered during multiple AMPH runs (Segal and Kuczenski, 1997a). Furthermore, various nonmonoamine systems [e.g., glutamate (Karler et al., 1989; Wolf and Khansa, 1991; Kalivas and Alesdatter, 1993; Stewart and Druhan, 1993; White et al., 1995)] are likely affected by the escalating dose-runs treatment and may contribute to the qualitatively distinct features of the altered behavioral profile.

In summary, our results suggest that the apparent decrease in the duration of the stereotypy phase and corresponding increase in the magnitude and altered qualitative features of the locomotor activation may be attributable to a progressive and persistent shift toward a predominance of mesolimbic DA transmission with repeated AMPH runs. These behavioral and neurochemical alterations may have important implications for the mechanisms underlying the addiction and induction of psychosis associated with high-dose stimulant abuse.

\section{REFERENCES}

Angrist B (1987) Clinical effects of central nervous system stimulants: a selective update. In: Brain reward systems and abuse (Engel J, Oreland L, eds), pp 109-127. New York: Raven.

Angrist B (1994a) Amphetamine psychosis: clinical variations of the syndrome. In: Amphetamine and its analogues (Cho AK, Segal DS, eds), pp 387-414. San Diego: Academic.

Angrist B (1994b) Psychosis-inducing effects of cocaine may show sensitization more than other effects. Neuropsychopharmacol 10:197S.

Axt KJ, Mamounas LA, Molliver ME (1994) Structural features of amphetamine neurotoxicity. In: Amphetamine and its analogs (Cho AK, Segal DS, eds), pp 315-367. San Diego: Academic.

Benet LZ, Mitchell JR, Sheiner LB (1990) Pharmacokinetics: the dynamics of drug absorption, distribution, and elimination. In: Goodman and Gilman's the pharmacological basis of therapeutics (Gilman AG, Rall TW, Nies AS, Taylor P, eds), pp 3-32. New York: Pergamon.

Benveniste H, Hansen AJ, Ottosen NS (1989) Determination of brain interstitial concentrations by microdialysis. J Neurochem 52:1741-1750.

Bowyer JF, Holson RR (1995) Methamphetamine and amphetamine neurotoxicity. In: Handbook of neurotoxicology (Chang LW, Dyer RS, eds), pp 845-870. New York: Marcel Dekker.

Bowyer JF, Tank AW, Newport GD, Slikker Jr W, Ali SF, Holson RR (1992) The influence of environmental temperature on the transient effects of methamphetamine on dopamine levels in rat striatum. J Pharmacol Exp Ther 260:817-824.

Bowyer JF, Gough B, Slikker Jr W, Lipe GW, Newport GD, Holson RR (1993) Effects of a cold environment or age on methamphetamineinduced dopamine release in the caudate putamen of female rats. Pharmacol Biochem Behav 44:87-98.

Butcher SP, Fairbrother IS, Kelly JS, Arbuthnott GW (1988) Amphetamine-induced dopamine release in the rat striatum: an in vivo microdialysis study. J Neurochem 50:346-355.

Cadoni C, Pinna A, Russi G, Consolo S, Di Chiara G (1995) Role of vesicular dopamine in the in vivo stimulation of striatal dopamine transmission by amphetamine: evidence from microdialysis and Fos immunohistochemistry. Neuroscience 65:1027-1039.

Castañeda E, Whishaw IQ, Lermer L, Robinson TE (1990) Dopamine depletion in neonatal rats: effects on behavior and striatal dopamine release assessed by intracerebral microdialysis during adulthood. Brain Res 508:30-39.

Church WH, Justice Jr JB (1987) Rapid sampling and determination of extracellular dopamine. Anal Chem 59:712-716.

Clausing P, Gough B, Holson RR, Slikker Jr W, Bowyer JF (1995) Amphetamine levels in brain microdialysate, caudate/putamen, substantia nigra and plasma after dosage that produces either behavioral or neurotoxic effects. J Pharmacol Exp Ther 274:614-621.

Costall B, Naylor RJ (1977) Mesolimbic and extrapyramidal sites for the mediation of stereotyped behavior patterns and hyperactivity by amphetamine and apomorphine in the rat. In: Cocaine and other stimulants (Ellinwood EH, Kilbey MM, eds), pp 47-76. New York: Plenum.

Davis JM, Schlemmer Jr FP (1980) The amphetamine psychosis. In: Amphetamines and related stimulants: chemical, biological, clinical and social aspects (Caldwell J, ed), pp 161-173. Boca Raton, FL: CRC.

Ellison G, Eison MS (1983) Continuous intoxication: an animal model of the acute psychotic episode. Psychol Med 13:751-761.

Ellison G, Eison MS, Huberman HS, Daniel F (1978) Long-term changes in dopaminergic innervation of caudate nucleus after continuous amphetamine administration. Science 276-278. 
Fischman MW, Schuster CR (1974) Tolerance development to chronic methamphetamine intoxication in the rhesus monkey. Pharmacol Biochem Behav 2:503-508.

Fischman MW, Schuster CR (1977) Long-term behavioral changes in the rhesus monkey after multiple daily injections of D-methylamphetamine. J Pharmacol Exp Ther 201:593-605.

Gawin FH (1991) Cocaine addiction: psychology and neurophysiology. Science 251:1580-1586.

Gawin FH, Khalsa ME (1996) Sensitization and "street" stimulant addiction. In: Neurotoxicity and neuropathology associated with stimulant abuse. NIDA Research Monograph Series (Majewska MD, ed), pp 224-250. Washington, DC: U.S. Government Printing Office.

Gibb JW, Hanson GR, Johnson M (1994) Neurochemical mechanisms of toxicity. In: Amphetamine and its analogs (Cho AK, Segal DS, eds), pp 269-295. San Diego: Academic.

Henry DJ, Greene MA, White FJ (1989) Electrophysiological effects of cocaine in the mesoaccumbens dopamine system: repeated administration. J Pharmacol Exp Ther 251:833-839.

Kalivas PW, Alesdatter JE (1993) Involvement of $N$-methyl-D-aspartate receptor stimulation in the ventral tegmental area and amygdala in behavioral sensitization to cocaine. J Pharmacol Exp Ther 267:486-495.

Kamata K, Rebec GV (1984) Long-term amphetamine treatment attenuates or reverses the depression of neuronal activity produced by dopamine agonists in the ventral tegmental area. Life Sci 34:2419-2427.

Karler R, Calder LD, Chaudhry IA, Turkanis SA (1989) Blockade of "reverse tolerance" to cocaine and amphetamine by MK-801. Life Sci 45:599-606.

Kelly P, Iversen SD (1976) Selective 60HDA-induced destruction of mesolimbic dopamine neurons: abolition of psychostimulant-induced locomotor activities in rats. Eur J Pharmacol 40:45-56.

Kuczenski R (1977a) Biphasic effects of amphetamine on striatal dopamine dynamics. Eur J Pharmacol 46:249-257.

Kuczenski R (1977b) Differential effects of reserpine and tetrabenazine on rat striatal synaptosomal dopamine biosynthesis and synaptosomal dopamine pools. J Pharmacol Exp Ther 201:357-367.

Kuczenski R (1979) Effects of para-chlorophenylalanine on amphetamine and haloperidol-induced changes in striatal dopamine turnover. Brain Res 164:217-225.

Kuczenski R, Segal DS (1989) Concomitant characterization of behavioral and striatal neurotransmitter response to amphetamine using in vivo microdialysis. J Neurosci 9:2051-2065.

Nash JF, Yamamoto BK (1992) Methamphetamine neurotoxicity and striatal glutamate release: comparison to 3,4-methylenedioxymethamphetamine. Brain Res 581:237-243.

Paulson PE, Robinson TE (1995) Amphetamine-induced timedependent sensitization of dopamine neurotransmission in the dorsal and ventral striatum: a microdialysis study in behaving rats. Synapse 19:56-65.

Pitts DK, Kelland MD, Freeman AS, Chiodo LA (1993) Repeated amphetamine administration: role of forebrain in reduced responsiveness of nigrostriatal dopamine neurons to dopamine agonists. J Pharmacol Exp Ther 264:616-621.

Roberts DCS, Zis AP, Fibiger H (1975) Ascending catecholamine pathways and amphetamine induced locomotion: importance of dopamine and apparent noninvolvement of norepinephrine. Brain Res 93:441-454.

Robinson TE, Whishaw IQ (1988) Normalization of extracellular dopamine in striatum following recovery from a partial unilateral 6-OHDA lesion of the substantia nigra: a microdialysis study in freely moving rats. Brain Res 450:209-224.

Schmidt CJ, Gehlert DR, Peat MA, Sonsalla PK, Hanson GR, Wamsley JK, Gibb JW (1985a) Studies on the mechanism of tolerance to methamphetamine. Brain Res 343:305-313.

Schmidt CJ, Sonsalla PK, Hanson GR, Peat MA, Gibb JW (1985b) Methamphetamine-induced depression of monoamine synthesis in the rat: development of tolerance. J Neurochem 44:852-855.
Schmidt D, Roznoski M, Ebert MH (1990) Qualitative and quantitative high performance liquid chromatographic analysis of monoamine neurotransmitters and metabolites in cerebrospinal fluid and brain tissue using reductive electrochemical detection. Biomed Chromatogr 4:215-220.

Schuster CR, Fischman MW (1996) Amphetamine toxicity: behavioral and neuropathological indexes. In: Current status of behavioral pharmacology. (Anonymous) pp 1845-1851. Rockville, MD: ASPET.

Segal DS, Kuczenski R (1987) Individual differences in responsiveness to single and repeated amphetamine administration: behavioral characteristics and neurochemical correlates. J Pharmacol Exp Ther 242:917-926.

Segal DS, Kuczenski R (1997a) An escalating dose "binge" model of amphetamine psychosis: behavioral and neurochemical characteristics. J Neurosci 17:2551-2566.

Segal DS, Kuczenski R (1997b) Repeated binge exposure to amphetamine and methamphetamine: behavioral and neurochemical characterization. J Pharmacol Exp Ther, in press.

Seiden LS, Sabol KE (1995) Neurotoxicity of methamphetamine-related drugs and cocaine. In: Handbook of neurotoxicology (Chang LW, Dyer RS, eds), pp 825-843. New York: Marcel Dekker.

Sessions G, Meyerhoff J, Kant GJ, Koob GF (1980) Effects of lesions of the ventral medial tegmentum on locomotor activity, biogenic amines and response to amphetamine in rats. Pharmacol Biochem Behav 12:603-608.

Stahle L, Segersvärd S, Ungerstedt U (1991) A comparison between three methods for estimation of extracellular concentrations of exogenous and endogenous compounds by microdialysis. J Pharmacol Methods 25:41-52.

Stewart J, Druhan JP (1993) Development of both conditioning and sensitization of the behavioral activating effects of amphetamine is blocked by the non-competitive NMDA receptor antagonist, MK-801. Psychopharmacology 110:125-132.

Swerdlow NR, Vaccarino FJ, Amalric M, Koob GF (1986) The neural substrates for the motor-activating properties of psychostimulants: a review of recent findings. Pharmacol Biochem Behav 25:233-248.

Swerdlow NR, Hauger R, Irwin M, Koob GF, Britton KT, Pulvirenti L (1991) Endocrine, immune, and neurochemical changes in rats during withdrawal from chronic amphetamine intoxication. Neuropsychopharmacology 5:23-31.

Tyler CB, Galloway MP (1992) Acute administration of amphetamine: differential regulation of dopamine synthesis in dopamine projection fields. J Pharmacol Exp Ther 261:567-573.

Wages SA, Church WH, Justice Jr JB (1986) Sampling considerations for on-line microbore liquid chromatography of brain dialysis. Anal Biochem 58:1649-1656.

Weihmuller FB, O’Dell SJ, Marshall JF (1992) MK-801 protection against methamphetamine-induced striatal dopamine terminal injury is associated with attenuated dopamine overflow. Synapse 11:155-163.

White FJ, Wang RY (1984) Electrophysiological evidence for A10 dopamine autoreceptor subsensitivity following chronic D-amphetamine treatment. Brain Res 309:283-292.

White FJ, Hu X-T, Zhang X-F, Wolf ME (1995) Repeated administration of cocaine or amphetamine alters neuronal responses to glutamate in the mesoaccumbens dopamine system. J Pharmacol Exp Ther 273:445-454.

Wolf ME, Khansa MR (1991) Repeated administration of MK-801 produces sensitization to its own locomotor stimulant effects but blocks sensitization to amphetamine. Brain Res 562:164-168.

Wolf ME, White FJ, Hu X-T (1994) MK-801 Prevents alterations in the mesoaccumbens dopamine system associated with behavioral sensitization to amphetamine. J Neurosci 14:1735-1745.

Zhang Y, Angulo JA (1996) Contrasting effects of repeated treatment vs withdrawal of methamphetamine on tyrosine hydroxylase messenger RNA levels in the ventral tegmental area and substantia nigra zona compacta of the rat brain. Synapse 24:218-223. 